\title{
Populistički Zeitgeist u “proevropskoj” Srbiji
}

\author{
ZORAN STOJILJKOVIĆ, DUŠAN SPASOJEVIĆ
}

Fakultet političkih nauka, Univerzitet u Beogradu

\begin{abstract}
Sažetak
Ovaj rad bavi se uticajem populističkih ideja na nastanak i organizaciju novih političkih partija u Srbiji nakon izbornih ciklusa 2007. i 2008. godine. Ovi izbori predstavljaju prelomnu tačku razvoja partijskog sistema jer nakon njih dolazi do formiranja proevropskog konsenzusa i vlade demokrata (Demokratska stranka, DS) i socijalista (Socijalistička partija Srbije, SPS), podele unutar Srpske radikalne stranke (SRS) i značajnog sužavanja ideološkog prostora koji zauzimaju relevantne stranke. Sa druge strane, visok stepen nepoverenja građana u politiku i niska ocena stanja demokratije podstiču pojavu novih aktera koji su, skoro po pravilu, pod značajnim uticajem svetskog talasa populizma. U radu primenjujemo ideacioni pristup populizmu i pokušavamo da na primeru novih političkih aktera pokažemo ideološke i organizacione varijacije koje mogu nastati pod uticajem populizma, kao i razlike koje se pojavljuju u interpretaciji populizma u Srbiji u odnosu na neke druge države.
\end{abstract}

Ključne riječi: populizam, Srbija, ideologije, političke partije, Srpska napredna stranka

U ovom tekstu razmatramo kakav je uticaj populizma i populističkih ideja na nastanak i razvoj novih političkih partija u Srbiji u poslednjih 10 godina, odnosno u periodu nakon 2008. godine. Nakon što je u izbornim ciklusima 2007-2008. godine ostvaren bazičan i plitak proevropski konsenzus društva, Srbija je ušla u novu fazu razvoja partijskog sistema. Ova faza preklapa se sa izbijanjem svetske ekonomske krize (2008), krize Evropske unije (sporo/neuspešno usvajanje ustava EU koje kulminira Brexitom), ali i pojavom novog talasa populističkih partija i lidera koji su iskoristili postkrizni kontekst da ozbiljno uzdrmaju temelje evropskih demokratija.

Simultanost ekonomske i političke krize na evropskom nivou se reflektovala i na unutrašnja politička pitanja u Srbiji. Uprkos očekivanju da započinje period stabilnosti i ubrzanih EU integracija, Srbija je nakon 2008. postepeno ušla u veoma 
turbulentnu i nestabilnu fazu političkog razvoja koja traje i danas. Izvor političke nestabilnosti (ali istovremeno i njen indikator), pored spomenutih i novonastalih kriza (migrantska kriza koja se na Evropu i Balkan preliva 2015. godine), predstavlja i velika volatilnost partijske scene i pojava značajnog broja novih partija i aktera. Skoro svi ovi novi akteri imaju populističke i antipartijske elemente, što sa jedne strane odslikava visok stepen nepoverenja građana u postojeće demokratske aktere i institucije, a sa druge strane dodatno produbljuje stepen političke krize i pokazuje da se populistički trendovi uspešno prenose i na zemlje u procesu pridruživanja EU. Ovaj period obeležen je usponom Aleksandra Vučića i Srpske napredne stranke koji postaju ubedljivo najvažniji i najsnažniji politički akter, preuzimaju vlast na svim nivoima i upravljaju Srbijom bez značajnijeg osporavanja od strane opozicije, što predstavlja određene elemente stabilnosti i izvesnosti u političkom životu.

U ovom radu analiziramo nove aktere koje su se pojavili nakon 2008. godine iz perspektive populizma i kroz dve osnovne dimenzije - ideološko-vrednosnu i organizacionu. Osnovna hipoteza ovoga rada je da se u ideološkoj ravni kod novih aktera skoro bez izuzetka mogu uočiti snažni populistički elementi, a da se iz sinergije populističkih ideja i dosadašnjeg predominantnog liderskog modela ustrojstva partija pojavljuje novi organizacioni oblik koji više podseća na političke pokrete sa snažnim liderom nego na klasične političke partije. U odnosu na obe dimenzije pokazujemo i kako se kod novih, tranzicionih demokratija u većoj meri pokazuje podložnost dominantnim trendovima koji oblikuju savremenu politiku (kao što su de-ideologizacija, profesionalizacija i/ili personalizacija politike), a koji se spajaju sa nedostacima mladih i institucionalno nekonsolidovanih demokratija i čine ih vidljivijim i uticajnijim. Populizam je jedan od najznačajnijih ishoda tih trendova i u tom kontekstu slučaj Srbije ima mnogo zajedničkog sa krizom demokratije u Poljskoj ili Mađarskoj, iako ćemo pokazati da postoje i određene značajne razlike.

Prvi deo rada posvećen je razmatranju osnovnih teorijskih koncepata važnih za ovaj rad, tj. pokušaju da se populizam što preciznije odredi i odvoji od pojmova/ fenomena/trendova koji ga često prate. Drugi deo rada analizira politički kontekst u Srbiji nakon 2008. godine kroz odgovor na pitanje u kojoj meri postojeći uslovi pogoduju nastanku populističkih pokreta i njihovom uspehu. U trećem delu rada analiziramo nove političke aktere - vladajuću Srpsku naprednu stranku (SNS), parlamentarne i opozicione stranke Dosta je bilo (DJB) i Dveri, kao i antipartijske aktere koji se pojavljuju na predsedničkim (2017) i lokalnim izborima u Beogradu (2018) - kandidata Ljubišu Preletačevića Belog i pokret Ne da(vi)mo Beograd. Sve spomenute aktere analiziramo kroz ideološku/programsku i organizacionu dimenziju. U zaključnom delu rada pokušavamo da pokažemo zbog čega su populističke ideje toliko uspešne u Srbiji, u kojoj meri su proizvod trenutnih okolnosti, a koliko 
dugoročnih trendova, na koji način su uklopljene u lokalni politički milje i da li je moguće na primeru Srbije pokazati raznovrsnost populističkih pristupa te razdvojiti populizam od sličnih/pratećih političkih pojava?

\section{Može li se populizam definisati i šta su uzroci njegove pojave?}

Populistička histerija proširila se svetom u poslednjoj deceniji, iako su populisti prisutni na političkoj mapi Evrope dosta dugo. Ipak, nasuprot relativno marginalnom položaju u stabilnim demokratijama i brzom odlasku sa vlasti (npr. slučaj austrijskog ÖVP-a (Österreichische Volkspartei) iz 1995), savremeni uspon populista obeležen je sposobnošću da se ove stranke zadrže na vlasti i da tokom vladanja ne izgube svoje karakteristične populističke elemente i podršku glasača (Albertazzi i Mueller, 2013). Uočavajući ovaj trend i u pomalo proročanskom maniru, nekoliko godina pre izbijanja aktuelne pomame izazvane Brexitom i pobedom Donalda Trampa na predsedničkim izborima u SAD-u, Mude (Mudde, 2004: 562) proglašava Populist Zeitgeist uz argument da je "populistički diskurs postao deo političkog mainstreama u zapadnim demokratijama". Na sličan način Ag (Agh, 2013) ističe da živimo u "Zlatnom dobu populizma" koje nastaje kao jedan od ishoda trostruke krize - krize transformacije (postsocijalističkih društava), krize nakon pristupanja EU i fiskalne krize iz 2015. Ipak, iako je populizam sveprisutan, kako u medijskopolitičkim tako i u akademskim krugovima, utisak je da je razumevanje ovog pojma veoma fluidno i skoro neuhvatljivo.

Jedan deo ove fluidnosti je potpuno razumljiv jer se etiketa populizma lepi na aktere koji se međusobno značajno razlikuju - na radikalne desničare i antiislamiste poput švajcarskog SVP-a (Schweizerische Volkspartei) ili holandskog PVV-a (Partij voor de Vrijheid), na regionaliste kao što je italijanska Lega Nord, na krila unutar velikih mainstream partija poput Korbinove struje u britanskim laburistima ili Trampovog dela republikanaca, na vladajuće stranke levog centra poput Sirize i na nove leve, građanske pokrete kao što je Podemos, da nabrojimo samo neke od uobičajenih sumnjivaca. Takođe, posebna poteškoća određivanja populizma je što ova reč ima prilično različita značenja u evropskim jezicima (Aalberg et al., 2016) te što populizam najčešće ima pežorativno značenje.

Zbog ove raznolikosti i potrebe da se populizam redefiniše u vrednosno neutralniji pojam, u ovom radu koristimo ideaciono i relativno minimalističko određenje pojma populizam. Prateći Mudea, populizam određujemo kao "ideologiju koja smatra da se društvo može podeliti na dve homogene i antagonističke grupe 'iskren narod' i 'korumpiranu elitu' te koja smatra da bi politika trebalo da bude izraz opšte volje (volonté générale) naroda" (Mudde, 2004: 562). Kako sam Mude navodi, populizam se zasniva na četiri koncepta - narodu, eliti, ideologiji i opštoj volji, ali se njegova suština može pronaći u ideji moralnosti jer se narod, koji je 
nosilac vrline, autentičnosti i čistote, sukobljava sa otuđenom i iskvarenom elitom (Mudde, 2017). Za razliku od drugih ideologija, populizam smatra da "su sve moguće razlike među pojedincima, poput, primjerice, klase, rase, socijalnoga statusa, profesije ili bilo kojega drugog socioekonomskog ili sociokulturnog obilježja nevažne u odnosu na zajedničku antagonizirajuću poziciju u odnosu na političke elite" (Šalaj i Grbeša, 2017: 326).

Populizam ipak nije izolovan od drugih ideologija, a ideacioni pristup nam omogućava da razumemo sinergiju koja se stvara između populizma i drugih ideoloških pravaca. Ideaciono razumevanje populizma objašnjava šarolikost fenomena konceptom ideologije tankog centra (thin-centered ideology) što podrazumeva da se populizam u političkoj realnosti uvek kombinuje sa drugim ideologijama omogućavajući varijacije od krajnje desnog do krajnje levog položaja. To bi, na primer, značilo da desni populizam kritikuje otuđenost političkih elita koje vodi ka umanjenju suvereniteta ili vrednosnoj, kulturnoj, verskoj ili etničkoj heterogenizaciji društva, dok levi populizam, između ostalog, smatra da je elita podređena ekonomskim interesima korporacija i da ne obraća dovoljno pažnju na interese običnog čoveka. Ovo nam jasno pokazuje da se osnovni elementi populizma - narod i elita, mogu razumeti i kao "prazni označitelji” (empty vessels ili empty signifiers) od čije intepretacije zapravo zavisi konkretizacija i vrednosno usmerenje populističke ideologije (Mudde, 2017).

Upravo zbog ove različite interpretacije osnovnih pojmova nije ni čudo da je značajan deo istraživačkih napora usmeren i na klasifikovanje različitih vrsta populizma. Potreba za klasifikacijom nije izražena samo unutar ideacionog pristupa, pa se kao dobar primer uticajne tipologije unutar pristupa koji populizam razmatraju kao stil komunikacije uzima Jagersova i Valgraveova podela na "prazni populizam" (koji podrazumeva samo pozivanje na narod), nasuprot "punom populizmu" (thicker populism) koji može biti “ekskluzivistički” (pozivanje na narod i ukazivanje na "druge" koji ne pripadaju narodu), antielitistički (pozivanje na narod pomešano sa antielitističkim idejama) i "potpuni populizam" koji obuhvata sve spomenute elemente (Jagers i Walgrave, 2007: 322-323). Za naše razmatranje je značajnije razlikovanje ekskluzivističkog i inkluzivističkog populizma (Mudde i Kaltwasser, 2013: 158-165) koje se može pratiti na tri nivoa - materijalnom (koji podrazumeva distribuciju određenih dobara od strane države ka ciljnim grupama ili njihovo isključivanje iz procesa distribucije), političkom (koji se odnosi na političko takmičenje i participaciju u Dalovom razumevanju termina (Dal, 1997)) i simboličkom (koji se odnosi na definisanje granica elite i naroda, odnosno određivanje ko pripada kojoj grupi). Načelno govoreći, inkluzivistički i levičarski populizam je karakterističan za Latinsku Ameriku, dok je ekskluzivistički i desničarski zastupljen u Evropi, iako se u političkoj realnosti mogu naći i mešoviti modeli. 
Ideacioni pristup se poslednjih godina profilisao kao najuticajniji pristup populizmu, naročito unutar politikoloških pristupa. Mude ističe četiri prednosti ideacionog pristupa: (1) mogu se postaviti jasne granice pojma kojima se populizam odvaja od "ne-populističkih fenomena", (2) omogućava formulisanje različitih kategorija, (3) primenjiv je u različitim društvima i omogućava poređenje i (4) može se primeniti na različite nivoe analize, tj. uključuje i stranu političke ponude i potražnje (Mudde, 2017).

Pored navedenog, ideaciono razumevanje nam omogućava da, sa jedne strane, iz definicije populizma isključimo pojave koje ga često prate poput: harizmatičnog lidera, načina komunikacije između lidera i naroda (Jagers i Walgrave, 2007) ili načina na koji populisti sprovode vlast (Antal, 2017; Müller, 2016), ali koje ne čine najmanji zajednički imenitelj za sve spomenute varijacije populizma. Istovremeno, ideacioni pristup može biti inkluzivan i kompatibilan sa spomenutim pristupima "jer smatra da su populističke ideje osnovna pokretačka snaga koja stoji iza onoga što opažamo (material features) kao populizam" (Hawkins i Kaltwasser, 2017: 515). U kontekstu teme ovoga članka posebno su nam važne teze da iz ideologije koju partija zastupa proizilazi način njene organizacije (Scarrow, 2005) i način njenog komuniciranja (Van Dijk, 1997), što nam omogućava da u drugom koraku u razmatranje uzmemo i ove elemente, ali tek kao posledicu ideološkog profila koji se uzima kao nezavisna varijabla.

Preteći ovu logiku, možemo zaključiti da iz ideologije konkretnog populizma proizilaze i načini razumevanja demokratije i sprovođenja politike - autoritarni ili iliberalni populisti (bez obzira da li dolaze sa levice ili desnice) često imaju problema sa mehanizmima liberalne demokratije poput sudske nezavisnosti, regulatornih ili kontrolnih tela i organa koji ograničavaju vladavinu većine (tj. vladavinu naroda ili opšte volje, kako ćemo često čuti), ali i sa principima podeljenog suvereniteta sa EU ili drugim nadnacionalnim entitetima. Sa druge strane, participativni populisti zagovaraju veće učešće građana u politici, koje može biti referendumskog tipa (i unutar predominantnog top-down procesa) ili grass-root učešće kakvo se zagovara u deliberativnim interpretacijama demokratije. U tom kontekstu je zanimljivo ukazati da Mude i Kaltvaser govore o tri (ideal)tipa mobilizacije kod populističkih partija: na osnovu ličnog liderstva (top-down pristup), društvenog pokreta (bottomup pristup) i političke partije (mešoviti pristup) (Mudde i Kaltwasser, 2017: 42-54). Kada je reč o prvom tipu, lider se stavlja u centar pažnje i predstavlja osnovu identifikacije sa biračima i centar okupljanja. To ne znači nužno da se formalno ne osniva politička partija, već da su njene strukture i organi fiktivni i da im je jedina funkcija podrška lideru tokom izborne kampanje. Ovakav scenario je verovatniji u prezidencijalističkim sistemima i sistemima sa slabo institucionalizovanim političkim partijama. Kod modela društvenog pokreta akteri su organizovani van-institucionalnim 
mehanizmima, kroz mrežne i autonomne forme, čime dodatno pokazuju svoj prezir prema etabliranim političkim partijama. Treći model mobilizacije, model političke partije, karakterističan je za evropski populizam i pokazuje da su stranke po pravilu efikasnije od pokreta (i neformalnih grupa), da mogu biti trajne i da mogu postati etablirani deo partijskih sistema. Veoma je važno ukazati da se u praksi veoma često sreće tzv. "dinamički model”, odnosno da se konkretni akteri često nalaze u prelaznim/razvojnim fazama između dva idealtipska modela.

Prednosti ideacionog pristupa možemo videti i u širem kontekstu problema koji razmatramo, jer nam omogućava da uspeh populizma interpretiramo kao rezultat nekoliko važnih procesa koji oblikuju savremene demokratije. Za početak, populizam se razume kao ishod de-ideologizacije i kartelizacije partijskih sistema (Katz i Mair, 1995). Oba procesa su dugoročna i sa jedne strane iskazuju stabilnost i konsenzus koji se postepeno gradi u periodu nakon šezdesetih godina 20 . veka, ali i okoštalost i institucionalno neprijateljstvo prema novim strankama i pokretima, naročito sa jasnim (ili intenzivnijim) ideološkim predznakom. Zbog toga nije ni čudo da još 1995. Kac i Mer pišu da se prostor za nove partije i osporavanje uspostavljenog konsenzusa otvara samo na krajevima političkog spektra i kroz formu ekstremno-desničarskih, nedemokratskih i ksenofobnih partija (ibid.: 24). U sličnoj argumentaciji de-ideologizacija dovodi do povećanja značaja lidera u odnosu na ostatak stranke - odnosno do prezidencijalizacije (Poguntke i Webb, 2005; Samuels i Shugart, 2010) i personalizacije (McAllister, 2007) politike, umanjenja značaja članstva i fleksibilizacije samog pojma (Gherghina, 2014; Gauya, 2015). Sve ovo ojačava otuđenost partijskog liderstva od članova, birača i samih građana (i sa druge strane stvara zavisnost od javnog položaja i javnih finansija), što otvara prostor da se kriza stranaka pretvori u krizu demokratije kao takve.

Zapravo, razumevanje osnovnih kritika savremene demokratije i narativa o krizi demokratije i političkih stranaka nam omogućava da razumemo politički i ideološki kontekst koji olakšava uspeh populističkih aktera. Jedna od takvih interpretacija je i koncept "partijskog paradoksa" koji ukazuje na to da se partije doživljavaju kao umiruće i nebitne institucije koje više ne predstavljaju nikoga, ali istovremeno i kao institucije koje imaju potpunu kontrolu nad političkim životom nacionalnih država (Becker i Cuperus, 2004), čime se suštinski povećava distanca između građana i političkih partija. Istovremeno, kontinuirani porast uticaja nadnacionalnih organizacija (sa ograničenim legitimitetom) i povećan broj odluka koje se donose van granica domašaja "običnih građana" ojačavaju percepciju o otuđenosti političkih elita i nemoći građana da utiču na donošenje odluka, o čemu govori pasivizacija građana između dva izborna ciklusa ili njihova aktivnost u veoma uskim policy poljima (Stojiljković, 2017). Rečnikom postdemokratije, današnja demokratija, između ostalog, može podrazumevati da "oligarhije nastale (izbornom) demokracijom 
pokušavaju djelovati neovisno o narodu" (Kursar, 2011). U pokušaju da ukaže na konkretnije dimenzije krize i smatrajući da kriza demokratije nema uvek jedan isti uzrok, Papas ukazuje na tri stuba posleratnih demokratija koja bivaju osporena od strane neprijatelja demokratije u 21. veku: demokratsku reprezentaciju, postepen napredak ka većoj integraciji Evrope i politički liberalizam (Pappas, 2016); ovim se pokazuje da kriza ima refleksiju na unutrašnji demokratski poredak, vrednosni sistem koji stoji iza poretka, ali i najvažniji spoljnopolitički i sigurnosni okvir Evropsku uniju. Iako se sadašnja kriza ne percepira samo kroz mehanizme reprezentativne i formalne/izborne demokratije (jer se atrofiranost ovih mehanizama vidi i kao jedan od indikatora krize), čak se i u proceni formalnog stanja demokratije vidi značajno opadanje standarda: kako pokazuje izveštaj Freedom Housea "Nations in Transit" za 2017. godinu, kod više od polovine zemalja se uočava opadanje nivoa demokratičnosti, a po prvi put od 1995. danas među tranzicionim i postsocijalističkim zemljama postoji više konsolidovanih autoritarnih režima nego konsolidovanih demokratija (Freedom House, 2017).

\section{Politički kontekst u Srbiji nakon 2008: da li je moguća ne-populistička politika u Srbiji?}

Politička scena u Srbiji je nakon restartovanja demokratske tranzicije usled petooktobarskih promena 2000. godine bila obeležena dubinskim sukobima oko ishoda $i$ brzine promena koje je trebalo sprovoditi. U odnosu na ova dva pitanja formirana su tri bloka: (1) modernistički, koji je zahtevao brze i temeljne promene, ponekad i na uštrb postojećeg pravnog poretka (blok je predvodila Demokratska stranka - DS), (2) blok stranaka starog režima koji je imao za cilj da delegitimizuje promene, da ih relativizuje i uspori braneći ideološko i političko nasleđe Slobodana Miloševića (blok su činile Socijalistička partija Srbije - SPS i Srpska radikalna stranka - SRS) i (3) blok stranaka (predvođen sa Demokratskom strankom Srbije - DSS) koji se pozicionirao u sredini i pokušao da zagovara proces postepenih promena i balansirao je između proevropskog i nacionalnog pristupa (Stojiljković i Spasojević, 2015). Srbija se po ovakvoj konstelaciji političkih snaga i rascepa donekle razlikovala od drugih istočnoevropskih, ali i postjugoslovenskih zemalja po sledećim karakteristikama: a) nakon demokratskih promena nije uspostavljen bazični konsenzus o evropskim i evro-atlantskim integracijama; b) snage starog režima su bez značajnije transformacije nastavile da funkcionišu na političkoj sceni i da se opiru uspostavljanju novih pravila igre i c) pitanje budućih odnosa sa Kosovom i Crnom Gorom je i dalje bilo otvoreno. Sve ove teme, kao i duboke podele koje su zbog njih nastale, veoma su uticale na tok tranzicije te kvalitet demokratije i demokratskih institucija, ali i na brzinu uspostavljanja novog ustavnog okvira (novi ustav je usvojen tek 2006. godine) i konsenzusa oko daljeg pravca razvoja države. Vrhunac polarizacije 
društva nastaje u periodu 2006-2008. godine kada dolazi do prekida EU integracija zbog nedostatka saradnje sa Haškim tribunalom, osamostaljenja Crne Gore i neuspeha u pregovorima sa Kosovom, što 2008. rezultira i jednostranim proglašenjem nezavisnosti (Mihailović, 2008). Polarizacija se uvećava vezanim izbornim ciklusima (parlamentarnim 2007. i 2008, predsedničkim 2008) koji bivaju odlučeni tesnom pobedom Borisa Tadića (DS) nad Tomislavom Nikolićem (SRS) u drugom krugu predsedničkih izbora i kasnijom odlukom SPS-a da formira vladu sa Tadićevim demokratama.

Srbija je nakon ovih izbornih ciklusa i važnih pobeda proevropskih i prodemokratskih snaga izvojevanih nad preostalim snagama starog režima očekivala period stabilnosti i ubrzanih evropskih integracija. Ova očekivanja osnažena su kada je liderstvo nacionalističkog SRS-a osnovalo umereniji SNS, prihvatilo EU integracije kao legitimni nacionalni cilj i odbacilo značajan deo radikalskog ideološkog prtljaga. Demokrate i socijalisti su povodom sklapanja vladajuće koalicije 2008. godine potpisali i Deklaraciju o istorijskom pomirenju, a sve su bile glasnije priče o mogućoj velikoj koaliciji naprednjaka i demokrata nakon narednih parlamentarnih izbora. Partijski sistem je nakon perioda polarizacije pokazivao skoro sve karakteristike umerenog pluralizma (Sartori, 2002) i delovalo je da se konačno uspostavlja kakva-takva stabilnost političkih aktera.

U odnosu na temu ovoga rada posebno je važna ideološka dimenzija ovog procesa. Nasuprot predominantno centrifugalnom političkom takmičenju koje je bilo zasnovano na politici identiteta i velikim pitanjima o Evropi i Kosovu, nakon izbora 2008. godine preovladavaju centripetalne sile i catch-all taktike vodećih stranaka. Tako se još pre izbora kod demokrata jasnije očitava politika "i Evropa i Kosovo", dok SNS pokušava da umanji spominjanje osetljivih vrednosnih pitanja i da na vrh političke agende postavi ekonomske teme. Na ovaj način partijski sistem Srbije prelazi važan put od dominacije "politike znamenja" ka dominaciji "politike interesa" (Pavlović i Antonić, 2007), odnosno dolazi do sužavanja ideološkog polja koje zauzimaju relevantne stranke (Stojiljković i Spasojević, 2013). Ovo sužavanje postaće najuočljivije nakon parlamentarnih izbora 2014. godine kada u Narodnu skupštinu ne ulazi ni jedna jedina antievropska stranka, što se delimično menja nakon vanrednih parlamentarnih izbora 2016. godine. Centripetalnost je još izrazitija ako se uzme u obzir distribucija glasova među partijama, odnosno da su stranke na ideološkim polovima poput Liberalno-demokratske partije (LDP), DSS-a, SRS-a i Dveri u ovom periodu imale problem da osvoje pet procenata glasova, koliko iznosi census za ulazak u parlament. Grafikon 1. prikazuje raspored političkih partija u dvodimenzionalnom ideološkom prostoru (Kitschelt, 1995) i njihovo centripetalno pomeranje u periodu od 2000. godine do danas, kao i položaj stranaka koje su nastale nakon 2008. godine. 
Grafikon 1. Sužavanje ideološkog prostora 2000-2018. i nastanak novih partija

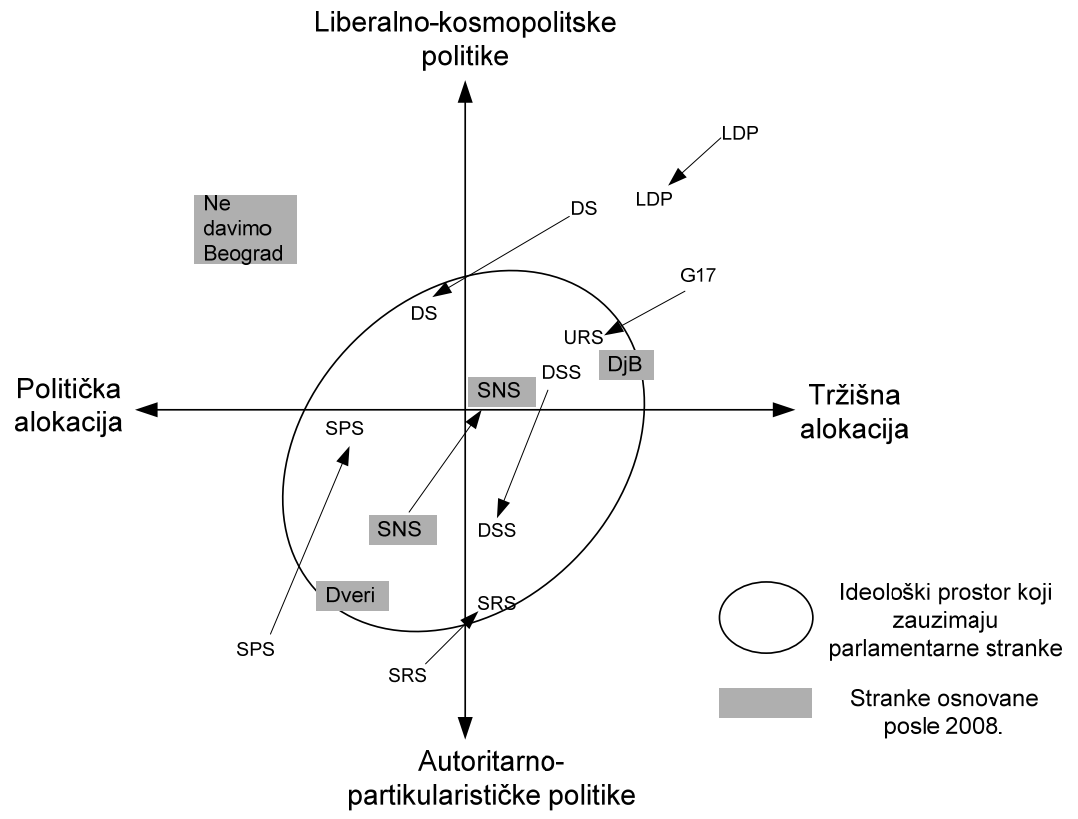

Izvor: prilagođeno na osnovu Stojiljković i Spasojević, 2013: 455.

Ipak, simultani uticaj svetske ekonomske krize i nesposobnost vlade DS-SPS da se ozbiljnije uhvati u koštac sa korupcijom i ekonomskim problemima koji su postajali sve očigledniji (Stojiljković, Z., 2012), doveli su do ponovnog stvaranja političke krize. U stranačkom smislu, kriza je otvorena tokom izbornog ciklusa 2012. godine, kada su istovremeno održani izbori na svim nivoima. Iznenadna pobeda naprednjaka Tomislava Nikolića $u$ drugom krugu predsedničkih izbora dovela je do nove vladajuće većine i formiranja vlade SPS-SNS-G17. G17 biva odstranjen tokom rekonstrukcije vladajuće većine u septembru 2013, a dvojac SNS-SPS nastavlja da vlada Srbijom (sa nekoliko manjih koalicionih partnera) uz konstantno uvećavanje političke moći Aleksandra Vučića (koji 2017. prelazi sa pozicije premijera na, ustavno gledano, slabiju poziciju predsednika Srbije) sa jedne strane i nemoć opozicije da se na ozbiljniji način suprotstavi SNS-u sa druge strane.

Kriza opozicije najočitija je na primeru DS-a koja se od sasvim zadovoljavajućeg rezultata od $22 \%$ na parlamentarnim izborima i Tadićevih $49 \%$ na predsedničkim izborima 2012. godine survala na 2,5\% na lokalnim izborima u Beogradu u martu 2018. DS je u međuvremenu promenio nekoliko lidera, pretrpeo jednu veliku 
podelu (odlazak Tadića i osnivanje Nove demokratske stranke (danas Socijaldemokratska stranka - SDS)) i konstantno bio pod surovim napadima vlasti i tabloida (iako su skoro sve afere završene bez sudskog epiloga). Kriza je u istom periodu pogodila i druge stare opozicione partije, pa se nekada veoma uticajan Koštuničin DSS nalazi ispod censusa za parlament, Šešeljev SRS povremeno uspeva da pređe izborni prag, a LDP Čedomira Jovanovića više nije ni u rangu statističke greške. Sve spomenuto otvorilo je političku scenu za ulazak novih aktera, suštinski smanjilo prag i stepen kartelizacije, povećalo nestabilnost partijskog sistema i konfuziju među ionako slabo partijski identifikovanim biračima.

Sa druge strane, politička kriza postojala je i pre 2012. godine i ne bi bilo opravdano svesti je samo na sudbinu pojedinih partija. Zapravo, kvalitet demokratije meren kroz stepen poverenja u političke institucije pokazuje konstantnost krize u Srbiji i njeno postepeno produbljivanje. U prilog ovoj tvrdnji govore nalazi javnomnenjskih istraživanja koji stepen poverenja u skupštinu, vladu ili predsednika Republike ne nalaze u iznosu višem od 30\% (u periodu 2006-2015), dok poverenje u političke partije pada i na $13 \%$ u 2013. ili na najnižih 6\% u 2015. godini (Stojiljković, Spasojević i Lončar, 2015). U odnosu na stanje demokratije u Srbiji mogu se formulisati četiri osnovna zaključka: (1) veoma je rašireno nezadovoljstvo funkcionisanjem krhkih institucija, (2) raširen je stav da je u "nekim situacijama nedemokratska vlada bolja (efikasnija, uspešnija) od demokratske" i (3) dominantno uverenje da "mi i nismo društvo zrelo za punu demokratiju", a (4) posebno je važan nalaz da postoji visoka korelacija između prihvatanja određenih političkih vrednosti i odnosa prema demokratiji, odnosno da postoji korelacija između nepoverenja u demokratiju i konzervativnih, tradicionalističkih i autoritarnih vrednosti (ibid.).

Iz ekonomskog ugla gledano, Srbiju je nakon 2008. pogodila ekonomska kriza. Nezaposlenost je sa $14,4 \%$ skočila na $24,4 \%$, uz istovremeni rast broja penzionera. Javni dug se gotovo udvostručio - porastao je sa 8,8 na 14,4 milijardi evra a da nije došlo do odgovarajućih pomaka u rastu proizvodnje i razvoju infrastrukture. $\mathrm{Na}$ drugoj strani, prosečna plata sve manjeg broja zaposlenih je u 2012. pala sa 409 na 333 evra (Stojiljković, Z., 2012).

Stepen nepoverenja u političke aktere otvorio je put pojavi novih igrača, ali i populističkim politikama zasnovanim na tezi o otuđenoj političkoj i ekonomskoj eliti. Sužavanje ideološkog polja koje je nastupilo pobedom proevropskih snaga i neprofilisanošću drugih političkih pitanja dovelo je do toga da se uske populističke platforme po ideološkoj dubini ne razlikuju puno od ostatka partijske ponude. $U$ takvoj situaciji može se reći da su ispunjeni svi uslovi za otpočinjanje zlatnog doba populizma i u Srbiji. 


\section{Novi akteri nakon 2008. godine - izazov populizma u kriznom kontekstu}

Iako se nakon 2008. godine činilo da Srbija ulazi u fazu političke stabilnosti, desio se potpuno suprotan scenario. U poređenju sa 2008. godinom, elementi kontinuiteta u Narodnoj skupštini su socijalisti čija se koalicija i danas nalazi na vlasti uz relativno sličnu izbornu snagu, demokrate i radikali sa mnogo manjim poslaničkim grupama, dok je više od polovine parlamenta popunjeno strankama koje pre 10 godina nisu ni postojale (Tabela 1). Pogledajmo zbog toga koji novi akteri su zauzeli političku scenu i šta su njihove osnovne ideje.

Tabela 1. Sastav Narodne skupštine Republike Srbije 2008. i 2018. godine

\begin{tabular}{|l|c|c|}
\hline & $\mathbf{2 0 0 8}$ & $\mathbf{2 0 1 8 .}$ \\
\hline Socijalistička partija Srbije & $7 \%$ (koalicija sa PUPS-JS) & $11 \%$ (koalicija sa JS) \\
\hline Demokratska stranka & $38 \%$ (koalicija sa G17) & $6 \%$ \\
\hline Demokratska stranka Srbije & $11 \%$ (koalicija sa NS) & $5 \%$ (koalicija sa Dveri) \\
\hline Srpska radikalna stranka & $29 \%$ & $8 \%$ \\
\hline Liberalno-demokratska partija & $5 \%$ & $5 \%$ (koalicija sa Novom DS) \\
\hline Srpska napredna stranka & $/$ & $48 \%$ \\
\hline Dosta je bilo & $/$ & $6 \%$ \\
\hline
\end{tabular}

Naravno, najvažnija stranka koja je nastala u ovom periodu je SNS i stepen volatilnosti partijskog sistema suštinski zavisi od toga da li ćemo SNS tumačiti kao novu ili kao stranku kontinuiteta. Iako bi se iz perspektive kontinuiteta moglo argumentovati da su liderstvo, infrastruktura i značajan broj birača u SNS stigli iz nekadašnjeg SRS-a, te da je reč o istoj stranci odnosno o stranci naslednici, iz ideološke perspektive SNS jeste napravio jasan otklon od SRS ideologije i tretiraćemo kao ga novu stranku, uz napomenu da radikalsko nasleđe i dalje ima uticaj na ideološki profil, imidž i identitet SNS-a.

Kao što je nastanak SNS-a bio interpretiran kao simbol pobede proevropske Srbije 2008. godine, tako su razlozi za ovu transformaciju od radikala ka naprednjacima, kao i politički uspeh nove stranke pokazatelji davno uočene potrebe SRS-a da se transformiše. Naime, iako je transformacija u SNS bila neočekivana za širu javnost, ne može se reći da ona nije bila planirana ili pripremana, odnosno da se $u$ ranijim potezima Nikolića i Vučića nije naslućivalo flertovanje sa ovom idejom. U taktičkom smislu, razlozi za transformaciju nalazili su se u činjenici da SRS nije imao nikakav koalicioni potencijal i da je uticaj stranke na politička dešavanja zbog toga bio marginalizovan (tj. odvijao se mehanizmima ucenjivačkog potencijala ko- 
ji podrazumeva uticaj na takmičenje drugih stranaka (Sartori, 2002)) i u nesaglasju sa biračkom snagom. Pored toga, ideološki profil birača SRS-a je pored nacionalno-konzervativne grupe podrazumevao i gubitnike tranzicije, odnosno ekonomske glasače koji bi uz stranku ostali i ukoliko bi se odrekla nacionalnog dela politike (Spasojević, 2016), a u javnosti se često spominjao i uticaj međunarodne zajednice na donošenje ovakve taktičke odluke (Jovanović, 2013).

Bez obzira na motivaciju, SNS je nastao 2008. godine kao stranka desnog centra, proevropskog opredeljenja. Osnovni taktički cilj u prvim godinama postojanja stranke je bilo stvaranje distance ka radikalskom nasleđu na način koji će omogućiti da se stranka percipira kao nešto novo, ali pri čemu ne bi trebalo iseći sve veze sa ovim biračkim telom. Uslovi i dominantne političke teme su pogodovali ovakvoj taktici, pa je SNS podržao pomeranje fokusa političke borbe sa pitanja Kosova i EU ka ekonomskim temama. To je sasvim očigledno u analizama prve kampanje za opšte izbore 2012. u kojoj SNS učestvuje nastupajući iz pozicije "pokreta nezadovoljnih" (ibid.: 13) koji obećava "radikalni obračun sa korupcijom i organizovanim kriminalom" i značajno smanjenje subvencija, ali i broja poslanika, ministarstava, agencija, zavoda i, generalno, državne administracije (Stojiljković, Z., 2012: 18) jer je "javni sektor preglomazan i prepun kadrova sada vladajuće koalicije" (Spasojević, 2012: 54). Ova neoliberalna pozicija ojačana je tezama o neophodnosti promene mentaliteta ("protestantski duh") i merama vlade zasnovanim na štednji u javnom sektoru (tzv. solidarni porez kojim su plate u javnom sektoru i penzije umanjene za 10\%).

Dve osnovne teme u kampanji SNS-a su bile ekonomija i korupcija i u interpretaciji ovih problema uočavamo jasne populističke elemente - SNS nastupa kao stranka običnog naroda i govori protiv otuđene elite koju čine DS i G17 (kao stranke simboli petooktobarskih promena, ali i tranzicione korupcije), tajkuni koji su se obogatili u sumnjivim privatizacijama (sa naglaskom na Miroslava Miškovića, vlasnika Delte) i međunarodna zajednica. U ovom tematskom okviru SNS se naslanja na postojeće nezadovoljstvo građana, koristi kritike koje dolaze iz EU (npr. priču o spornim privatizacijama) i domaćih organizacija civilnog društva (npr. kritiku Društva sudija Srbije zbog loše reforme sudstva ili kampanju za "bele listiće") u pokušaju da profitira na veoma niskom stepenu poverenja u institucije i lošoj oceni stanja demokratije u Srbiji. Istovremeno, SNS nudi rešenja koja se kreću unutar postavljenog okvira evropskih integracija i demokratskog društva (za razliku od nekadašnje SRS-ovske pozicije) i posledično onemogućava političke konkurente da plaše birače pričom o "povratku u devedesete". Zapravo, u klasičnom populističkom narativu SNS se pozicionira kao stranka koja brani demokratski režim od uzurpatora koji su prevarili narod. 
Ipak, u ovoj analizi ne želimo da tvrdimo da je SNS isključivo populistička stranka, već da su populističke ideje sastavni i važan deo njegovog ideološkog profila, kao i da mu daju određeni legitimitet, osvežavaju staro ruho i pojačavaju identifikaciju među biračima. Dobar primer ovog populističkog "osvežavanja" ideologije je i razumevanje drugog (the Other) u ideologiji SNS-a. Ovo pitanje je bilo dosta osetljivo i primetno je da su naprednjaci činili sve da ga izbegnu; sa druge strane, novo biračko telo nije toliko drugačije od starog i određena doza neprijateljstva prema drugima je morala biti zadržana - dve osnovne outgroups za SNS su međunarodna zajednica i zemlje/narodi regiona. Ipak, $u$ obe ove dimenzije, $u$ poređenju sa SRS-om, naprednjaci imaju mnogo mekšu poziciju, koriste nejasnije formulacije i pokušavaju da naprave diferencijaciju između "neprijatelja". Tako se afirmativno govori o EU integracijama, ali se istovremeno Brisel kritikuje za rigidan ili čak antisrpski stav, dok se o uticajnim državama članicama (npr. Nemačkoj ili Austriji) govori u superlativima. U odnosu na regionalne teme, SNS ističe da je za pomirenje i regionalnu saradnju, ali istovremeno, na primer, ističe kritike na račun položaja Srba u Hrvatskoj koji "ne doprinosi regionalnoj saradnji i unapređenju odnosa dve države" (Stojiljković, A., 2012). Ova slojevitost (i delimična kontradiktornost) poruka će vremenom sve više rasti, pa će se unutar stranke javiti podela posla u odnosu na komunikaciju sa različitim ciljnim grupama. U najvećem broju slučajeva predsednik stranke Vučić biće zadužen za pomirljive tonove i smirivanje strasti, dok će njegovi bliski saradnici imati ulogu pokretača verbalnog konflikta (npr. ministri Vulin i Stefanović tokom migrantske krize u odnosu prema zvaničnom Zagrebu). U ideološkom smislu, ova heterogenost je moguća jer se SNS pozicionirao kao predominantna stranka (i predvodnik koalicije koja ima oko 50\% biračkog tela) koja sprovodi sveobuhvatnu (catch-all) taktiku. Ovo je značajna taktička prednost koju SNS sebi može da priušti za razliku od manjih, ideološki profilisanijih stranaka; takođe, ova prednost dolazi do izražaja kada SNS kao stranka vlasti mora istovremeno da održava podršku interesno i ideološki sukobljenih grupa.

Zapravo, ideološka pozicija SNS-a se dobro može razumeti u poređenju sa još jednom novom strankom desnice koja je nastala nakon 2008. godine. Reč je o stranci Dveri koja je formalno registrovana 2015. (iako od 2012. ima politički aktivnu organizaciju koja učestvuje na izborima) i koja se može razumeti kao suverenistički i tradicionalistički odgovor na petooktobarske promene. Dveri su zanimljive jer su, za razliku od većine partija u Srbiji, nastale iz društvenog pokreta Dveri i potisnutog, u javnosti slabo prisutnog desnog, nacionalističkog i konzervativnog civilnog društva.

Za razliku od drugih desnih stranaka koje svoje pozicije primerno grade na pitanjima nacionalizma, Kosova i antievropejstva (i koje u ideološkom kontekstu možemo da razumemo kao rezultat rascepa/procesa koji nastaju kao ishod raspada Jugoslavije), Dveri su primarno profilisane kao konzervativna partija koja govori o 
pravoslavlju, tradiciji i porodičnim vrednostima. To ne znači da se Dveri ne zalažu za opstanak Kosova u sastavu Srbije, niti da su evrofilne, već da su kulturno-vrednosni stavovi o društvenim pitanjima u prvom planu ove stranke (Vukov, 2013), kao i da stranka koristi upražnjeni ideološki prostor koji nastaje povlačenjem SNS-a ka centru i smanjenjem političkog uticaja SRS-a.

Dveri su najbolji primer nove desnice i populizma u Srbiji. Snažan diskurs o "odnarođenim elitama" koje su preuzele vlast nakon 2000. godine Dveri čini najbližim idealtipskom modelu novih zapadnoevropskih populista; ova bliskost ojačana je idejom o Briselu kao centru moći koji nameće vrednosti koje su suprotne narodnom i većinskom uverenju, ali i snažnim antiimigrantskim stavovima, iako je migrantsko pitanje u Srbiji ostalo periferno, čak i tokom dve godine migrantske krize. Dveri se i u ekonomskim politikama slažu sa zapadnoevropskim pandanima zagovarajući ekonomski protekcionizam i olakšavanje položaja domaćim privrednicima u odnosu na globalnu konkurenciju. Populistička dimenzija očituje se i u činjenici da Dveri "oštro kritikuju ne samo vladajuće stranke, već i ceo partijski i stranački sistem" (ibid.: 414).

Upravo na kritici partijskog i političkog sistema nastao je još jedan novi politički projekat - pokret Dosta je bilo (u prvoj fazi često nazivan i Restart!). Ovaj pokret osnovao je Saša Radulović, ministar finansija u kratkotrajnoj vladi SNS-SPS koja je formirana 2013. nakon izlaska URS-a iz vlade (vlada je trajala do 2014. i raspisivanja vanrednih izbora). Radulović je u vladu ušao kao nepartijska (ekspertska) ličnost, ali nije bio nepoznata politička figura jer je pisao blogove o ekonomskim temama. Prilikom izlaska iz vlade Radulović je kritikovao "nesprovođenje najavljenih reformi, partijsko zapošljavanje i visok nivo korupcije i netransparentnosti u celokupnom radu Vlade" (Avakumović, 2017: 161), čime je definisao i buduću ideološku poziciju DJB-a - naglasak na transparentnosti i odgovornosti, utemeljen na idejama meritokratije (kao negacije stranačkog zapošljavanja i postavljanja nestručnih ljudi na javne funkcije) i neoliberalizma (iako zavijenog u kritiku visokih subvencija koje država Srbija daje stranim investitorima). Relativni uspeh DJB-a i visok intenzitet podrške koji je imao među članovima i biračima pokazuju da su odabrane teme dosta dugo potiskivane sa političke agende, ali da su (iako sa različitim interpretacijama) prisutne kod većine novih stranaka. Tako na primer, DJB deli ideju smanjenja javnog sektora i kritiku subvencionisanja stranih poslodavaca sa SNS-om (naročito u opozicionoj fazi SNS-a), dok sa Dverima deli kritiku partijskog i političkog sistema. Ipak, kako se DJB u svom antipartizmu eksplicitno ne poziva na narod, niti zagovara antipluralističke ideje, stranka se ne može klasifikovati kao populistička. Takođe, igranje na kartu meritokratije, obrazovanja i stručnosti DJB-u daje određenu dozu elitizma, što se u vidi i u načinu prezentovanja njegovih ideja, ljudima koji istupaju ispred stranke, ali i profilu biračkog tela. 
Tri kratko analizirane stranke predstavljaju najvažnije nove političke aktere nastale nakon 2008. godine. Ipak, ovaj spisak ne bi bilo opravdano zatvoriti bez spominjanja dva kandidata koja su igrala značajnu ulogu na predsedničkim izborima 2016. godine i jedne nove građanske liste koja je učestvovala na važnim lokalnim izborima u Beogradu 2018.

U medijskom smislu, ali i u odnosu na našu temu, svakako je najviše pažnje privukla pojava Ljubiše Preletačevića Belog, fiktivnog lika (koga je na izborima "igrao" Luka Maksimović) i predsednika fiktivne stranke SPN (Sarmu prob'o nisi). Beli je, nastupajući iz satirične pozicije, svojim imenom i argumentacijom kritikovao korupciju, profesionalizaciju politike, učestalu praksu preletanja iz stranke u stranku i otuđenost političara od naroda. Njegova parodijska (i izuzetno viralna) kampanja bila je zasnovana na sloganu "Samo jako" i uključivala je očigledno preterana obećanja biračima, lažnu kupovinu glasova i malverzacije, kao i brojne parodije na uobičajene kampanje u Srbiji od kojih je svakako vizuelno najupečatljivije bilo pojavljivanje kandidata na belom konju. Beli je na ovim izborima osvojio 9,5\% glasova iako je bio kritikovan od strane opozicione javnosti kao neko ko skreće pažnju birača sa pravih tema. Ipak, kao kandidat koji je otvoreno kritikovao Vučića nije bio aktivno napadan od drugih opozicionih kandidata, a lider DJB-a Saša Radulović je čak aktivno podržao njegovu kandidaturu (nakon što je propao pokušaj da se opozicija ujedini oko zajedničkog kandidata). Pojava Belog (ali i njegov kasniji politički neuspeh) nam u značajnoj meri govori o stepenu nepoverenja građana $\mathrm{u}$ političke aktere i potrazi za novim opcijama, ma kako komične i neutemeljene one bile. U ideološkom smislu, Beli se više može razumeti kao simbol antipartizma i prezira prema političarima, a manje kao eksponent populizma, iako se u njegovim idejama (ma kako parodijske bile) mogu uočiti populističke dimenzije.

Kao svojevrsni kontrateg populističkom talasu u Srbiji možemo spomenuti kandidaturu Saše Jankovića na predsedničkim izborima. Janković je poslednjih osam godina radio kao prvi izabrani Ombudsman, tj. zaštitnik građana, ali je najveću pažnju javnosti dobio nakon afere Savamala (rušenje nekoliko zgrada u naselju Savamala u izbornoj noći 2016. od strane maskiranih lica; može se pretpostaviti da su zgrade srušene jer su smetale kontroverznom projektu Beograd na vodi) kada je ušao u sukob sa vladom Aleksandra Vučića u pokušaju da natera nadležne organe da izvrše istragu. Janković je na predsedničkim izborima nastupio uz podršku DS-a i brojnih istaknutih intelektualaca (tzv. Apel 100) koji su bliski građanskom, liberalnom krilu, ali i drugim strankama nekadašnje Demokratske opozicije Srbije (DOS, koalicije koja je 2000. godine porazila Miloševića). Jankovićev ideološki profil nije bio populistički; ipak, i kod njegove kandidature se uočavaju elementi nezadovoljstva postojećim strankama - on nastupa kao novo, nepolitičko lice, kao stručnjak dokazan u svojoj oblasti, a podrška DS-a (od izuzetnog značaja u smislu 
infrastrukture, političkog iskustva i rada na terenu) se taktički sakriva zbog njenog lošeg rejtinga.

Konačno, izbori za Skupštinu grada Beograda (uvek od velikog značaja zbog političkog, ekonomskog kapitala prestonice i velikog broja birača) doneli su i pojavu nove leve grupacije - građanske liste Ne da(vi)mo Beograd! Ova lista izrasla je na protestima protiv projekta Beograd na vodi i afere Savamala, ali je i ranije kritikovala urbanistička rešenja, podređenost krupnom kapitalu, premala ulaganja $u$ javne prostore i generalnu komercijalizaciju grada. Imajući to u vidu, $\mathrm{Ne}$ da(vi)mo Beograd je po svom ideološkom profilu bliska španskim građanskim inicijativama Ahora Madrid (Madrid sada) i Barselona en comu (Barselona za nas) te predstavlja levu varijaciju populizma koja insistira na otuđenosti političkih elita, distanci od političkih partija i uvođenju građana (budući da je termin narod u srpskom jeziku prepoznat kao deo nacionalne, suverenističke tradicije) u politiku.

Naravno, detaljnije poređenje šest spomenutih aktera bilo bi neopravdano i teško izvodljivo zbog velike razlike u njihovoj političkoj moći, periodu postojanja i razvijenosti ideoloških platformi. Za ovu analizu najvažnije je bilo ukazati na zajedničke motive koji stoje iza ovih kandidatura i zajedničke ideološke koncepte, ali i na veoma različite intepretacije sličnih problema.

U odnosu na klasifikaciju populizma na inkluzivistički i ekskluzivistički, jasno je da u Srbiji preovlađuje evropski, desni i ekskluzivistički model. Ovaj model je najčistiji kod Dveri koje zagovaraju redistribuciju javnih resursa kako bi ojačale porodične vrednosti ili domaće privrednike (materijalni nivo), zagovaraju ograničavanje rada nevladinih organizacija i međunarodne pomoći za civilno društvo (politički nivo) i bore se protiv migranata, profesionalnih političara i "pete kolone" iz civilnog sektora (simbolički nivo). Ekskluzivistički populizam SNS-a je najočigledniji u odnosu na politički nivo jer se stepen političkog takmičenja smanjuje gušenjem parlamentarne opozicije i opstrukcijom rada skupštine od strane većine, marginalizovanjem nezavisnih medija, kontrolnih i regulatornih tela i civilnog društva. Dodatno, kroz simboličku dimenziju se vrši delegitimizacija opozicije narativom o "korumpiranim elitama iz prethodne vlasti" i "tajkunima koji su opljačkali narod i državu". Imajući u vidu načelnu sveobuhvatnu i centrističku ideološku tendenciju SNS-a, pozicija stranke je najmanje izgrađena u odnosu na materijalni nivo jer se ne može govoriti o toliko jasnoj redistribuciji resursa ka ciljnim grupama, sa izuzetkom klijentelističkih i koruptivnih odnosa koji ne korespondiraju u potpunosti sa ideološki proklamovanim ciljevima. Konačno, u kratkom periodu postojanja $\mathrm{Ne}$ da(vi)mo Beograd je pokazao inklinaciju ka levom i inkluzivističkom razumevanju populizma kroz otvaranje politike za marginalizovane grupe ili zagovaranje redistributivnih mera u odnosu na ono što definiše kao javni interes (npr. javni prostori), nasuprot uticaju privatnih ili partikularnih interesa. 
Imajući u vidu izneto, stiče se utisak da se može govoriti o veoma različitim razumevanjima populizma, kao i ideološkim pozicijama koje su blizu populističkog polja, ali ne spadaju u njega. Pogledajmo sada da li između njih postoje neke zajedničke karakteristike u vezi sa organizacionom dimenzijom i načinom na koji razumeju vođenje politike.

\section{Organizacioni modeli novih aktera}

Razmatranje načina organizacije i načina bavljenja politikom u kontekstu populizma ima značajno mesto pre svega zbog određenog broja autora koji populizam definišu kao način vođenja politike ili kao način komuniciranja sa biračima. U oba pristupa nailazimo na argumente da populisti više vole neformalne organizacije predvođene moćnim/harizmatičnim liderom i direktno komuniciranje sa biračima, uz izbegavanje mainstream medija i uz obilno korišćenje društvenih mreža. Ideacioni pristup ne negira značaj organizacione dimenzije ni načina na koji stranka komunicira sa biračima, ali ga razume kao ishod ideološkog profila stranke, a ne kao nezavisan fenomen. U kontekstu istraživanja novih aktera u Srbiji imamo nameru da istaknemo nekoliko zaključaka: (1) populistička ideologija može dati različite organizacione ishode, u zavisnosti od toga šta je host ideology koju stranka ima; (2) populistički Zeitgeist se preklapa sa brojnim trendovima koji oblikuju savremenu politiku (npr. profesionalizacija, personalizacija i prezidencijalizacija), pa se između njih javlja snažna sinergija i (3) efekti spomenutih trendova su uvek kulturološki uslovljeni, tj. u velikoj meri zavise od dominantnog oblika političkog organizovanja, političke kulture i naslanjaju se na postojeće obrasce i praksu. Drugim rečima, (uspešan) populizam je uvek nacionalno kontekstualizovan i prilagođava se lokalnim običajima i praksi.

Zbog ovog uticaja konteksta važno je da podsetimo da su političke partije u Srbiji obeležene snažnim liderima čija moć leži u formalnim ovlašćenjima i neformalnim mehanizmima partijske discipline, u kojima partijske oligarhije institucionalnim mehanizmima kontrolišu sve partijske organe, uključujući čak i glavni odbor i partijski kongres (Stojiljković i Spasojević, 2016). U ovakvim partijama pozicija članstva je pasivna i marginalizovana, a sama stranačka infrastruktura nerazvijena. Relativna nestabilnost partijskog sistema i česte promene otežavaju uspostavljanje stabilnih odnosa i unutarstranačke demokratije, pa se o organizacionom kontinuitetu može govoriti samo u slučaju SPS-a, DS-a i SRS/SNS-a (Spasojević i Stojiljković, 2018).

Zapravo, novonastajući model organizovanja stranaka se dobro uočava u tranziciji od radikala ka naprednjacima. SRS je bio organizovan kao hijerarhizovana i centralizovana stranka iza snažnog predsednika - Vojislava Šešelja (Bochsler, 2010). SNS je sa Vučićevim preuzimanjem stranke od Nikolića, a zatim i njegovim formalnim preuzimanjem vlasti (na poziciji premijera i predsednika) došao u 
fazu da stranka ima neospornog lidera od koga sve zavisi i ogroman broj partijskih članova - oko 700.000 (iako su podaci o broju članova partija u Srbiji nepouzdani, smatra se da je Miloševićev SPS na vrhuncu imao oko 600.000 članova). SNS je, dakle, odličan primer prezidencijalizacije i personalizacije politike u situaciji u kojoj masovni mediji i društvene mreže omogućavaju liderima stalnu i direktnu komunikaciju sa biračima, ali i unapređuju mehanizme partijske discipline i nadzora. SNS za sada ne gradi trajniju, autonomnu i funkcionalnu partijsku strukturu, što omogućava Vučiću da ima nesputanu vlast i da drži partijske zvaničnike pod konstantom pretnjom smene u slučaju loših rezultata ili nedostatka discipline. Kada se na ovo doda nadmoć u javnom prostoru koju Vučić ima zahvaljujući uticaju na medije, onda se stvara sinergija između više faktora. U odnosu na ono što se često razume kao model populističke komunikacije, može se reći da Vučić više koristi klasične mehanizme, tj. prisustvo u masovnim medijima u odnosu na starije biračko telo, dok je stranačka infrastruktura angažovana na društvenim mrežama, u pisanju komentara (što u internetskom prostoru rade tzv. botovi) i u odnosu na mlađi deo biračkog tela.

Nešto drugačiji trendovi su uočljivi kod novih opozicionih partija koje nemaju ravnopravan pristup javnom servisu (Radio-televiziji Srbije) ni brojnim neskriveno provladinim medijskim kućama (TV Pink i TV Happy, pre svega), pa se okreću drugačijim mehanizmima vođenja politike. Kao što smo već napomenuli, Dveri su stranka koja je izrasla iz desnih i konzervativnih organizacija civilnog društva. Ipak, zbog izraženog antipartijskog stava Dveri su u prva dva izborna ciklusa nastupile kao građanska lista, a sama odluka da se formalno registruju kao stranka 2015. godine je izazvala sukobe unutar organizacije. Dveri u komunikaciji sa biračima u velikoj meri koriste društvene mreže pokušavajući da nadoknade manjak prisustva u masovnim medijima, ali i da bi održali direktnu vezu sa svojom bazom i bliskim grass-root organizacijama.

Donekle sličan pristup ima i DJB, iako za razliku od Dveri nema korene u civilnom društvu. DJB formalno funkcioniše kao pokret jer ima administrativne probleme da se registruje kao stranka (ime stranke je već zauzeto u registru političkih partija). U svojoj organizaciji su pokušali da primene različite neuobičajene mehanizme - otvoren proces izrade programskih dokumenata, korišćenje softvera koji bi na meritokratskim principima odredili kandidate za poslanike i njihov redosled na listi, a pred izbore 2016. je čak i objavljen javni "poziv građanima koji podržavaju politiku DJB da se kandiduje za poslanike ili odbornike kako bi se na listama našli i ljudi koji do tada nisu bili članovi pokreta" (Avakumović, 2017: 161). DJB je usled nedostatka novca i pristupa mainstream medijima svoje kampanje po pravilu izvodio preko društvenih mreža (gde su aktivni svi viđeniji članovi pokreta), čime dodatno ističe svoju razliku u odnosu na ostale aktere i ostvaruje direktnu komuni- 
kaciju sa biračima. Ipak, utisak je da ovi mehanizmi nisu dali očekivane rezultate u izgradnji organizacije, jer je pokret ušao u krizu nakon izbora 2018. godine kada je grupa narodnih poslanika (isključenih iz stranke zbog neslaganja) optužila rukovodstvo za nedemokratske tendencije.

Sa sličnim problemima suočiće se i inicijativa Ne da(vi)mo Beograd! koja za sada funkcioniše kao federacija nekoliko organizacija i neformalnih grupa. Tokom kampanje deo aktivnosti je podrazumevao direktne razgovore sa građanima u mesnim zajednicama koje Ne da(vi)mo Beograd pokušavaju da politički revitalizuju. Inicijativa u svom radu dosta koristi performanse i druge inventivne oblike privlačenja pažnje građana i medija. Takođe, pokušava da promoviše princip antiliderstva i da u ime inicijative istupaju različiti aktivisti (iako se, naravno, ovaj krug ne može beskonačno širiti).

Ukratko, novi akteri nemaju razgranatu infrastrukturu, što se od većine i ne može očekivati zbog kratkog trajanja, dok je kod SNS-a reč o planskom kreiranju predominantnog lidera. U odnosu na Mudeovu trojnu tipologiju populističke mobilizacije (liderska/društveni pokret/politička stranka), jasno je da SNS koristi za evropske populiste uobičajen model političke partije koji u kontekstu niskog stepena institucionalizacije partijskog sistema i prezidencijalizacije pojačava ulogu predsednika stranke do maksimuma i očekivano uvodi elemente liderskog modela. Sa druge strane, kod Dveri i Dosta je bilo! je uočljiva postepena transformacija od modela društvenog pokreta ka klasičnom partijskom modelu, dok se u dosada kratkom trajanju Ne da(vi)mo Beograd oslanja na koncept društvenog pokreta. Dakle, utisak je da svi novi akteri pokušavaju da nađu nove organizacione mehanizme u nameri da povećaju distinktivnost u odnosu na stare partije, ali i da se u tom procesu suočavaju sa ustaljenim autoritarnim i liderskim obrascima političke kulture u Srbiji.

\section{Zaključna razmatranja}

Iako Srbija nije u prvom planu kada se govori o poslednjem talasu populizma, više nego očigledno je da se populističke ideje lako uočavaju kod novih aktera koji se pojavljuju u Srbiji. To, naravno, ne znači da među starim strankama ne postoje populističke ideje - na kraju krajeva, Mude je klasifikovao stari SRS kao populističku stranku (Mudde, 2000), ali se kod novih stranaka ove ideje očituju u većoj meri. To je pre svega posledica podsticajnih uslova koji postoje na političkoj sceni - sa jedne strane izuzetan stepen nepoverenja u političke aktere i uverenje u otuđenost $i$ korumpiranost političkih (ali i ekonomskih) elita, a sa druge strane izuzetno sužen ideološki prostor, što omogućava da "tanke" populističke ideologije i izborne platforme ne deluju nerazvijeno.

U odnosu na savremeni talas populizma, slučaj Srbije je zanimljiv jer pruža brojne varijacije populističkih politika. U poređenju sa drugim istočnoevropskim 
zemljama, Srbija ima očigledne zajedničke karakteristike sa Mađarskom i Poljskom jer se u sve tri zemlje na vlasti nalaze populističke stranke koje dominiraju partijskim sistemom. Ipak, slučaj SNS-a je dodatno intrigantan jer je SNS stranka formalno proevropske orijentacije i jer, za razliku od Fidesza i PiS-a, pokušava da izbegne identitetna pitanja kao osnovnu liniju prepoznavanja. Ova taktika je posledica transformacije SNS-a ka centru političkog spektra i pokušaja da se umanji ideološki prtljag koji je stranka nasledila iz radikalskog perioda. Ipak, ideološki profil SNS-a nije tako jednostavan - niti je u pitanju samo populistička stranka, niti su se u potpunosti odrekli nacionalističke politike i prihvatili proevropsku agendu. Zapravo, reč je o dobro osmišljenom programskom balansu koji stranka održava; činjenica da je SNS zauzeo centar političke scene, da ima veliku podršku birača i slabu i podeljenu opoziciju olakšava mu takvo ponašanje. Takođe, ovako složen ideološki profil nam pokazuje adaptabilnost populizma, kao i mogućnost da se populističke ideje zadrže i kada stranka dođe na vlast.

Stranka koja se najviše uklapa u dominantni model savremenih populističkih stranaka su Dveri - stranka nove desnice, koja promoviše pravoslavne vrednosti i antiimigrantske stavove. Stranka je zanimljiva zato što kombinuje uobičajene nacionalističke elemente sa društvenim konzervativizmom, što nije bio slučaj ni kod SRS-a ni kod SPS-a (stranaka koje su najviše profilisane kroz nacionalizam, odnosno kroz nasleđe Miloševićeve politike). Na drugoj strani političkog spektra pojavila se inicijativa $\mathrm{Ne}$ da(vi)mo Beograd koja interpretira populizam na levom krilu kroz antielitističku i antipartijsku poziciju, participaciju građana i direktnu demokratiju.

U odnosu na distinkciju između inkluzivističkog i ekskluzivističkog populizma, jasno je da je Srbija primer dominacije drugog modela, koji je najizraženiji na primeru Dveri, ali se po kriterijumu uticaja na politički život populizam najviše pojavljuje kroz naprednjačko manihejsko razumevanje politike, delegitimizaciju opozicije i oštre sukobe sa skoro svim neistomišljenicima. Uverenje da većinska vlast ne može biti osporavana ni ograničavana je jedno od ključnih izvora iliberalnih tendencija u Srbiji, koje ugrožavaju same temelje izborne demokratije i urušavaju ionako niske demokratske standarde.

Konceptualna mapa populizma u Srbiji nam omogućuje i da ukažemo na granice između populizma i sličnih pojava. U ideološkom smislu to je najočiglednije kod Dosta je bilo! čiji antipartizam i želja "da ovi odu, a da se oni ne vrate" (slogan sa poslednjih izbora) nisu podržani antielitističkim stavovima en général, niti pozivanjem na narod, što nam omogućava da ih razdvojimo od populističke grupe. Sa druge strane, nacionalističke ideje i korišćenje koncepta "drugog" kod SRS-a ili SPS-a (što često koriste u spoljno-političkim ili regionalnim pitanjima) nisu po sebi populizam ukoliko nedostaje jasno interpretiranje podeljenosti društva kroz opozi- 
ciju narod-elita. No, veoma uočljivi trendovi personalizacije i prezidencijalizacije kod SNS-a (ali i kod drugih partija) po sebi nisu populistički. Ipak, kada premijer Vučić direktno prima građane u svojoj kancelariji i time zamenjuje predstavničku funkciju parlamenta i drugih institucija u čije nadležnosti se meša, može se govoriti o jasnim populističkim idejama.

U odnosu na način organizovanja stranaka, populistički elementi su vidljivi u direktnoj komunikaciji sa biračima i korišćenju društvenih mreža da bi se izbegli/ nadomestili nedostaci komuniciranja preko masovnih medija. Takođe, u Srbiji nalazimo sva tri modela populističke mobilizacije - liderski, partijski i društveni pokret, i to u teorijski očekivanom dinamičnom modelu koji podrazumeva istovremeno postojanje više modela kod pojedinačne stranke.

Ipak, čini se da u odnosu na organizacioni nivo populističke politike imaju manji uticaj, odnosno da prevagu odnose tradicionalni, liderski modeli organizovanja na koje se, u nekim slučajevima, kaleme populističke inovacije. Dominacija tradicionalnog organizovanja je uočljiva i kod Dveri i DJB-a koji uprkos participativnim tendencijama i direktnom komuniciranju ne uspevaju da se otrgnu od oligarhijskih tendencija i prezidencijalizacije stranaka. Naravno, u slučaju SNS-a ova tendencija dobija preovlađujući karakter stvarajući od ove stranke najveći politički projekat u istoriji partijskog pluralizma u Srbiji.

\section{LITERATURA}

Aalberg, Toril, Esser, Frank, Reinemann, Carsten, Strömbäck, Jesper i de Vreese, Claes (ur.). 2016. Populist political communication in Europe. Routledge. New York.

Agh, Atilla. 2013. The triple crisis in Hungary: The "Backsliding" of Hungarian Democracy after Twenty Years. Romanian Journal of Political Science (PolSci), (13), 1: $25-51$.

Albertazzi, Daniele i Mueller, Sean. 2013. Populism and Liberal Democracy: Populists in Government in Austria, Italy, Poland and Switzerland. Government and Opposition, (48), 3: 343-371.

Antal, Atilla. 2017. The political Theories, Preconditions and Dangers of the Governing Populism in Hugary. Politologicky Časopis/Czech Journal of Political Science, vol. 1: 6-21.

Avakumović, Lana. 2017. Programska platforma liste Dosta je bilo - Saša Radulović na parlamentarnim izborima 2016. godine, u: Pilipović, G. i Stojiljković, Z. (ur.): Stranke i javne politike - izbori u Srbiji 2016. godine. Konrad Adenauer Stiftung. Beograd: 161-182. 
Becker, Frans i Cuperus, Rene. 2004. The Party Paradox: Political Parties Between Irrelevance and Omnipotence. A View from the Netherlands. Europäische Politik, 06/2004: 2-16.

Bochsler, Daniel. 2010. The party system of Serbia, u: Stojarova, V. i Emerson, P. (ur.): Party Politics in the Western Balkans. Routledge. London i New York: 99-118.

Dal, Robert. 1997. Poliarhija. Filip Višnjić. Beograd.

Freedom House. 2017. Nations in transit: The false promise of populism. Freedom House. Washington D.C.

Gauja, Anika. 2015. The construction of party membership. European Journal of Political Research, (54), 2: 232-248.

Gherghina, Sergiu. 2014. Shaping parties' legitimacy: Internal regulations and membership organisations in post-communist Europe. International Political Science Review, (35), 3: 291-306.

Hawkins, Kirk i Kaltwasser, Cristóbal Rovira. 2017. The Ideational Approach to Populism. Latin American Research Review, (52), 4: 513-528.

Jagers, Jan i Walgrave, Stefaan. 2007. Populism as political communication style: An empirical study of political parties' discourse in Belgium. European Journal of Political Research, 46: 319-345.

Jovanović, Milan. 2013. Parlamentarni izbori u Srbiji 2012. godine - rezultati i političke posledice, u: Jovanović, M. i Vučičević, D. (ur.): Izbori u Srbiji 2012. godine: (Ne)očekivana promena. Institut za političke studije. Beograd: 9-30.

Katz, Richard i Mair, Peter. 1995. Changing models of party organisation and party democracy: the emergence of the cartel party. Party politics, (1), 5: 5-28.

Kitschelt, Herbert. 1995. The Formation of Party Cleavages in Post-communist Democracies. Party Politics, (1), 4: 447-472.

Kursar, Tonči. 2011. Sporna demokracija: novi prilozi raspravi. Političke perspektive, (1), 1: 85-96.

McAllister, Ian. 2007. The Personalization of Politics, u: Dalton, R. i Klingemann, H.-D. (ur.): The Oxford Handbook of Political Behavior. Oxford University Press. Oxford: 571-588.

Mihailović, Srećko. 2008. Stare i nove linije ideološko-vrednosnog rascepa. Oko izbora, 17: 7-22.

Mudde, Cas. 2000. In the Name of Peasantry, the Proletariat, and the People: Populisms in Eastern Europe. East European Politics and Societies, (14), 2: 33-53.

Mudde, Cas. 2004. The Populist Zeitgeist. Government and Opposition, (39), 2: 541563.

Mudde, Cas. 2017. Populism: An Ideational Approach, u: Kaltwasser, C. R. i dr. (ur.): The Oxford Handbook of Populism. Oxford University Press. Oxford: 27-47. 
Mudde, Cas i Kaltwasser, Cristóbal Rovira. 2013. Exclusionary vs. Inclusionary Populism: Comparing Contemporary Europe and Latin America. Government and Opposition, (48), 2: 147-174.

Mudde, Cas i Kaltwasser, Cristóbal Rovira. 2017. Populism. Oxford University Press. Oxford.

Müller, Jan-Werner. 2016. What is Populism? University of Pennsylvania Press. Philadelphia.

Pappas, Takis. 2016. Distinguishing Liberal Democracy's Challengers. Journal of Democracy, (27), 4: 22-36.

Pavlović, Dušan i Antonić, Slobodan. 2007. Konsolidacija demokratskih ustanova u Srbiji posle 2000. godine. Službeni glasnik. Beograd.

Poguntke, Thomas i Webb, Paul. 2005. The Presidentialization of Politics in Democratic Societies: A Framework for Analysis, u: Poguntke, T. i Webb, P. (ur.): The Presidentialization of Politics: A Comparative Study of Modern Democracies. Oxford University Press. Oxford: 1-25.

Samuels, David i Shugart, Matthew. 2010. Presidents, Parties, and Prime Ministers: How the Separation of Powers Affects Party Organization and Behaviour. Cambridge University Press. New York.

Sartori, Giovanni. 2002. Stranke i stranački sustavi. Politička kultura. Zagreb.

Scarrow, Susan. 2005. Beyond Party Members. Changing Approaches to Partisan Mobilization. Oxford University Press. Oxford.

Spasojević, Dušan. 2011. Odblokirana tranzicija - političke podele u Srbiji nakon 2000. godine. Godišnjak Fakulteta političkih nauka, (5): 119-138.

Spasojević, Dušan. 2012. Socio-ekonomske teme u izbornoj kampanji 2012, u: Stojiljković, Z. i Pilipović, G. (ur.): Javne politike u izbornoj ponudi. Konrad Adenauer Fondacija. Beograd: 51-71.

Spasojević, Dušan. 2016. Serbian Political Parties and the Kosovo Question, u: Mehmeti, L. i Radeljić, B. (ur.): Kosovo and Serbia: Contested Options and Shared Consequences. Pittsburgh University Press. Pittsburg: 106-126.

Spasojević, Dušan. 2017. Može li populizam biti vladajuća ideologija?, u: Simendić, M. (ur.): Demokratski otpori normalizaciji autoritarizma. Udruženje za političke nauke Srbije, Fakultet političkih nauka. Beograd: 75-91.

Spasojević, Dušan i Stojiljković, Zoran. 2018. Strong Leaders, Passive Members, and State-Dependency in Serbia, u: Gherghina, S., Iancu, A. i Soare, S. (ur.): Party Members and Their Importance in Non-EU Countries. Routledge. London: 148168.

Stojiljković, Ana. 2012. Spoljna politika i politički sistem - ima li politika u izbornim kampanjama?, u: Stojiljković, Z. i Pilipović, G. (ur.): Javne politike u izbornoj ponudi. Konrad Adenauer Fondacija. Beograd: 31-50. 
Stojiljković, Zoran. 2012. Izborna obećanja i postizborna realnost: javne politike u izbornoj ponudi u Srbiji, u: Stojiljković, Z. i Pilipović, G. (ur.): Javne politike u izbornoj ponudi. Konrad Adenauer Fondacija. Beograd: 9-24.

Stojiljković, Zoran. 2017. Neoliberalni populizam lokalnih stabilokrata iliti kako da korporativni vukovi ne parališu strahom (sindikalne) ovce?, u: Simendić, M. (ur.): Demokratski otpori normalizaciji autoritarizma. Udruženje za političke nauke Srbije, Fakultet političkih nauka. Beograd: 175-197.

Stojiljković, Zoran i Spasojević, Dušan. 2013. Programske pozicije i unutarstranački odnosi stranaka u Srbiji nakon izbora 2012., u: Stojiljković, Z., Pilipović, G. i Spasojević, D. (ur.): (Ne)demokratsko redizajniranje političkih partija u Srbiji. Konrad Adenauer Stiftung. Beograd: 441-462.

Stojiljković, Zoran i Spasojević, Dušan. 2015. Partijski sistem Srbije, u: Stojiljković, Z., Spasojević, D. i Lončar, J. (ur.): Kako internu stranačku demokratiju učiniti mogućom? Fakultet političkih nauka, CeMI. Beograd, Podgorica: 49-68.

Stojiljković, Zoran i Spasojević, Dušan. 2016. Organizational Structures of Political Parties in Serbia, u: Sobolewska-Myslik, K., Kosowska-Gastol, B. i Borowiec, P. (ur.): Organizational Structures of Political Parties in Central and Eastern European Countries. Jagiellonian University Press. Krakow: 369-390.

Stojiljković, Zoran, Spasojević, Dušan i Lončar, Jelena. 2015. Da li je populizam neizbežan sastojak politike u Srbiji?, u: Knežević-Predić, V. (ur.): Politički identitet Srbije u globalnom i regionalnom kontekstu. Fakultet političkih nauka. Beograd: 37-50.

Šalaj, Berto i Grbeša, Marijana. 2017. Što je populizam i kako ga istraživati? Društvena istraživanja, (26), 3: 321-340.

Van Dijk, Teun. 1997. Ideology. Sage Publications. London, Thousand Oaks, New Delhi.

Vukov, Tamara. 2013. Pokret Dveri, u: Stojiljković, Z. Pilipović, G. i Spasojević, D. (ur): (Ne)demokratsko redizajniranje političkih partija u Srbiji. Konrad Adenauer Stiftung. Beograd: 409-418. 


\section{Zoran Stojiljković, Dušan Spasojević: \\ THE POPULIST ZEITGEIST IN “PRO-EUROPEAN” SERBIA}

\section{Summary}

In this paper we analyze the influence of populist ideas on the emergence and organization of new political parties in Serbia after the elections in 2007 and 2008. These elections represent the turning point in the development of the party system because only after the pro-European consensus among Democrats and Socialists was formed, the division within Serbian Radical Party occurred and the ideological space occupied by the relevant parties has narrowed. On the other hand, high level of distrust in politics among the citizens and lowering of the state of democracy facilitate the emergence of new actors who are, almost by rule, under the influence of the growing wave of populism in the world. In this paper, we apply the ideational approach to populism and, using the new actors as example, we aim to identify ideological and organizational variations which can develop under the influence of populism, as well as differences which emerge from the interpretation of populism in Serbia compared to some other countries.

Keywords: Populism, Serbia, Ideologies, Political Parties, Serb Progressive Party

Zoran Stojiljković je redovni profesor na Fakultetu političkih nauka Univerziteta u Beogradu.

Dušan Spasojević je docent na Fakultetu političkih nauka Univerziteta u Beogradu. Kontakti:

Zoran Stojiljković, Fakultet političkih nauka, Jove Ilića 165, 11000 Beograd, Srbija. E-mail: zoran.stojiljkovic@fpn.bg.ac.rs

Dušan Spasojević, Fakultet političkih nauka, Jove Ilića 165, 11000 Beograd, Srbija. E-mail: dusan.spasojevic@fpn.bg.ac.rs 